\title{
Toward understanding the 2019 Coronavirus and its impact on the heart
}

\author{
Richard C. Becker ${ }^{1}$
}

Published online: 15 April 2020

○) Springer Science+Business Media, LLC, part of Springer Nature 2020

The purpose of human life is to serve, and to show compassion and the will to help others.

\section{Albert Schweitzer}

The 2019 Coronavirus (CoV) (SARS-severe acute respiratory syndrome $\mathrm{CoV}-2$ ) (SARS-CoV-2)pandemic has gripped the world's population in profound and unprecedented ways, ranging from social, economic, and geopolitical to healthcare equity, public policy and a larger than life opportunity for renewed and robust dialogue about national health coverage. One is reminded that equity and social justice in medicine have several well-known categories for defining population health- social determinants, primary prevention, secondary prevention and tertiary prevention. While the Coronavirus pandemic of 2020 tests the rigor of each determinant, and scaledoperations at the local, community, regional, national and international levels, the early focus has centered on vulnerability, that historically has tracked social conditions and primary prevention with a critical goal of achieving virus containment and carefully planned resource utilization.

The medical and scientific communities have a major role to play. They must collectively determine the nature of the Coronavirus, its pathogenicity, transmission, reproduction number, potential treatment and the need for immunization for the near-and longer-term, respectively. Gathering and sharing rigorously obtained and carefully vetted information of the highest scientific integrity will make a major contribution to global efforts on behalf of human health.

The available data derived from initial reports and, more recently case series of patients with SARS-CoV-2 infection, referred to as COVID-19 (Coronavirus-associated disease) has consistently shown a high incidence of cardiac injury, heart failure, circulatory shock and arrhythmias.

Richard C. Becker

beckerrc@ucmail.uc.edu

1 Cincinnati, USA
The following brief editorial is designed to summarize our current understanding of SARS-CoV-2 and its effects on the heart. Several potential and expected effects based on virology precedent are also discussed. Updates will be provided in the coming weeks as our knowledge expands and further matures.

\section{The beginning of COVID-19 in humans}

While the first case of SARS-CoV-2 causing COVID (CO' stands for 'corona,' 'VI' for 'virus,' and ' $\mathrm{D}$ ' for disease- initially called 2019 novel Coronavirus" or "2019-nCoV) may have occurred as early as November of 2019, the earliest reported symptoms have been traced to December 1, 2019 [1]. On December 31, 2019 the World Health Organization (WHO) China Country office was informed about cases of pneumonia of unknown cause detected in Wuhan City, Hubei Province of China. An initial evaluation of these cases was undertaken. Four lower respiratory tract samples, including broncho-alveolarlavage (BAL) fluid, were collected from patients in Wuhan and compared with seven samples collected from patients in Beijing who had pneumonias of known cause [2]. More than 20,000 viral reads from individual specimens were obtained and most matched the genome from lineage $\mathrm{B}$ of the genus beta-Coronavirus showing greater than $85 \%$ identity with a bat SARS-like CoV.

Between December 31, 2019 and January 3, 2020, 44 cases of patients with pneumonia of unknown cause were reported to the WHO by National authorities in China. On January 11th and 12th of 2020, the Chinese National Health Commission identified the source of exposures at a seafood market in Wuhan City (Huanan Seafood Wholesale Market) (Fig. 1). A cohort of forty-one cases caused by SARS-Cov-2 was reported by Huang et al. [1]. A majority $(30[73 \%])$ were men with a median age of 49.0 years (IQR 41.0-58.0). Common initial symptoms included fever $(40[98 \%])$, cough $(31[76 \%])$ and myalgias or fatigue (18[44\%]). All 41 patients had bilateral, 


\section{CORONAVIRUS TIMELINE}

Both SARS and COVID-19 emerged in China, but authorities have been faster to respond to the latest outbreak.

SARS outbreak New coronavirus outbreak November 2002 December 2019

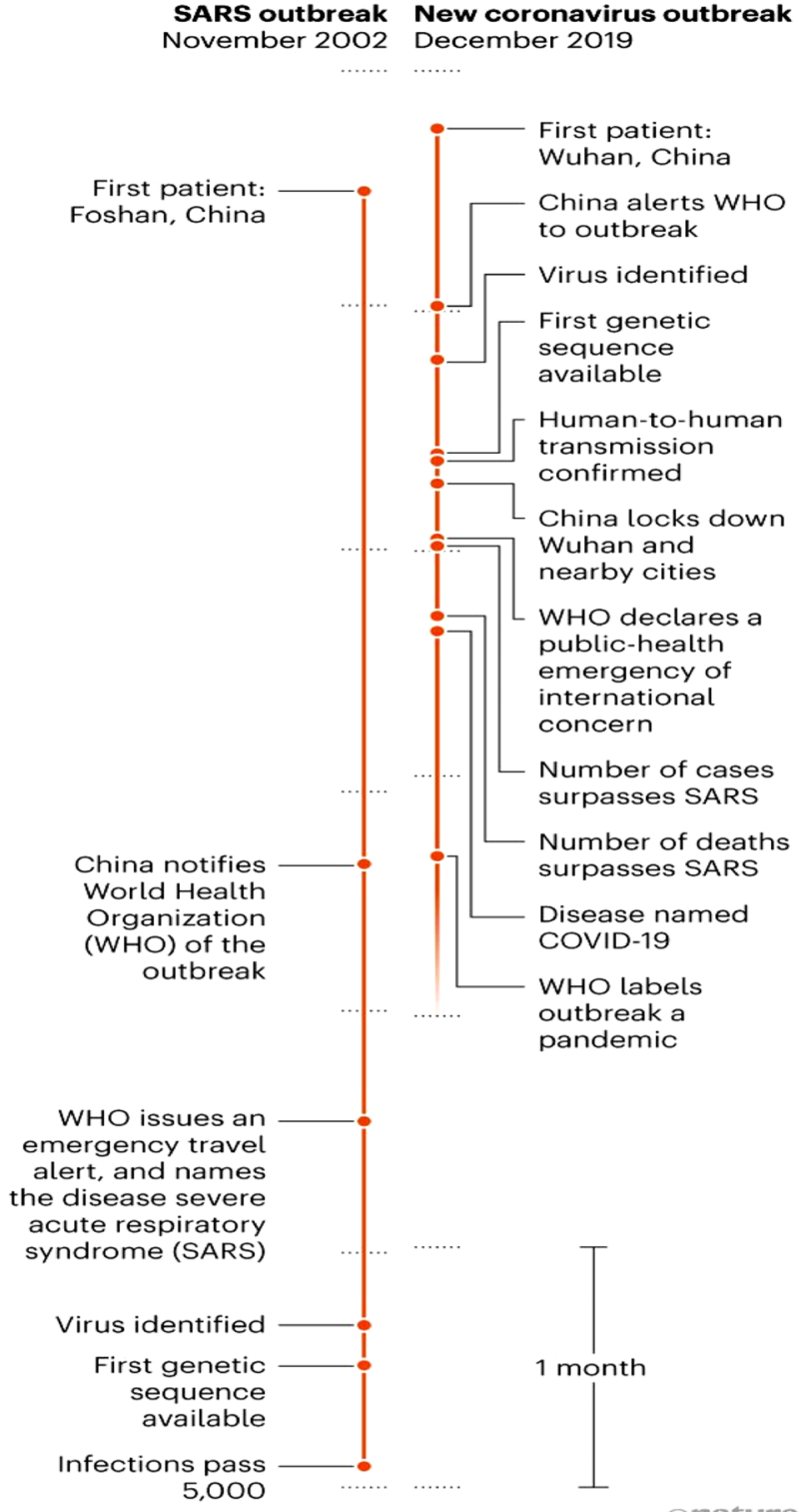

(c) nature

Fig. 1 Timelines for the SARs-CoV outbreak in 2002 and the more recent SARS-CoV-2 outbreak leading to COVID-19. Identification, responses and clinical impact are highlighted and contrasted. Severe acute respiratory syndrome (SARS); coronavirus $(\mathrm{CoV})$; coronavirusassociated illness (COVID)-19 From Callaway E. Nature Briefing Newsletter. March 18, 2020. With permission

multi-lobar pneumonia with abnormal findings on chest computed tomography (CT) scans. Most patients were both leukopenic (low white blood cell count) and lymphopenic $\left(<1.0 \times 10^{9} / \mathrm{L}\right)$ on hospital admission. D-dimer levels were elevated, particularly among patients that required intensive care unit (ICU)-level care (median D-dimer level
$2.4 \mathrm{mg} / \mathrm{L}$ vs $0.5 \mathrm{mg} / \mathrm{L}$ ). A majority of patients had normal procalcitonin levels $(<0.1 \mathrm{ng} / \mathrm{ml})$.

The first confirmed case of COVID-19 in the United States was a 35-year-old man in Snohomish County, Washington who presented to an urgent care center after 4-days of cough and subjective fever [3]. He had recently returned to Washington State after visiting family in Wuhan, China. Viral panels for routine respiratory pathogens were negative. Nasopharyngeal and oropharyngeal swabs were sent to the Center for Disease Control and Prevention (CDC) following notification of the Washington State Department of Health. Both swabs were positive for SARS-COV-2. Progressive bilateral infiltrates on chest $\mathrm{x}$-ray, a new requirement for supplemental oxygen and persistent fevers on day 6 prompted initiation of treatment with remdesivir (see subsequent section on potential treatments under study). Serial negative procalcitonin levels and negative cultures for bacterial pathogens prompted discontinuation of vancomycin and cefepime. Rapid clinical improvement was observed over the next 24-48 h.

\section{The virus responsible for COVID-19}

Coronaviruses belong to the subfamily Coronavirineae in the family of coronavitidae of the order nidovirales. The subfamily includes: Alpha Coronavirus, Beta Coronavirus, Gamma Coronavirus and Delta Coronavirus [4, 5]. The genome is a single-stranded positive-sense RNA (30 kb) with a 5' cap structure and a 3'-poly-A tail. The SARS-CoV-2 virus belongs to the cluster of beta coronaviruses originating most likely from horseshoe bats. Homotrimers of S proteins make up the spikes on the virus surface and enable binding to host receptors. In the case of COVID-19 oral-pharyngeal cell angiotensin converting-enzyme (ACE)-2 is the primary receptor. Of the 20 other known pathogenic Coronaviruses (6 of which can infect humans), an overwhelming majority are associated with respiratory infections and syndromes of varying severity-the most pathogenic Coronaviruses that can cause fatal pulmonary infections and multi-organ system failure are SARS-CoV, MERS-CoV and SARS-CoV-2 [6-8].

Coronaviruses contain at least 6 open-read frames (ORFs). ORFs near the 3' terminal of the genome encode primary structural proteins; spike (S), membrane (M), envelope (E) and nucleocapsid (N). As mentioned previously, S proteins are responsible for attachment to host receptors. $\mathrm{M}$ proteins contain transmembrane domains that contribute to virus shape, curvature and binding to the nucleocapsid. The E protein is involved with virus assembly and pathogenesis. $\mathrm{N}$ proteins package and encapsulate the genomes into virions and antagonize innate proteins and silencing RNA [9-12].

The trimeric SARS-CoV-2 surface S protein consists of three S1S2 heterodimers that bind the cellular receptor 
ACE2 and mediate fusion at the viral and cellular membranes through a "pre-to-post" fusion conformational change. The available information obtained by cryo-electron microscopy shows that only one receptor-binding domain binds ACE2 and adopts an upward conformation [13] (Fig. 2). Moreover, binding to the receptor opens up the receptor binding domain of S1 and promotes the release of the S1-ACE2 complex and S1 monomers. Soluble complexes can bind to host cell unoccupied ACE2 receptors. The available data suggest that the combinant receptor binding domain (RBD) portion of the SARS-CoV-2 S protein has evolved to effectively target ACE2. The SARS-CoV-2 S protein is so effective at binding human cells that the scientific community has concluded it is the result of natural selection [14-16]. The same is true of its backbone and overall molecular structure [17].

Population genetic analyses of 103 SARS-CoV-2 genomes indicated that these viruses evolved into two major types (designated $\mathrm{L}$ and $\mathrm{S}$ ), that are well defined by two different single nucleotide polymorphisms (SNPs). Further, the analyses showed near complete linkage across the viral strains sequenced to date. Although the L type ( 70\%) is more prevalent than the $\mathrm{S}$ type $(\sim 30 \%)$, the $\mathrm{S}$ type is believed to be the ancestral version. Whereas the L type was more prevalent in the early stages of the outbreak in Wuhan, China the frequency of the L type decreased after early January 2020. Human intervention may have placed more severe selective pressure on the L type, which might be more aggressive and spread more quickly $[16,18]$.

The unique characteristics of SARS-CoV-19 as initially determined in December 2019 suggested strongly that humans would not possess "herd immunity" i.e. an absence of prior exposure made existing antibodies to SARS-CoV-19 unlikely. This, in turn, should have signaled alarms about potential infectivity and robust immune and resulting inflammatory responses to infection. The burst of inflammatory cells and proteins, often referred to as "cytokine storm" is believed to have been responsible for many deaths during the 1918 flu pandemic, H5N1 bird flu outbreaks, and the 2003 SARS outbreak $[19,20]$. The unique characteristics of the virus, to include its stability and large scale of infected people also suggest strongly that there will be "second or multiple waves" of SARS-CoV-2 in the coming years.

\section{SARS-CoV-2 binding and infectivity}

Angiotensin converting enzyme II (ACE2) is the receptor to which SARS-CoV-2 binds and invades human cells [21]. Zou et al. constructed a risk map of human organs utilizing single-cell RNA sequencing data sets derived from major human physiological systems. Analysis of the available data identified the organs at risk for SARS-CoV-2 infection and specific cell types with ACE2 expression. The most vulnerable organs and cell types are as follows: lung (type II alveolar cells), heart (myocardial cells), kidney (proximal tubule cells), ileum and esophagus (epithelial cells) and bladder (urothelial cells) (Fig. 3).ACE2 receptors are also found in both venous and arterial endothelial cells and in arterial smooth muscle cells [22]. The expression of ACE2 receptors increases with age, but varies little by either sex or race under normal circumstances [23, 24].

The binding of SRS-CoV-2 to ACE2 is a necessary step for virus entry, followed by multiplication, spread
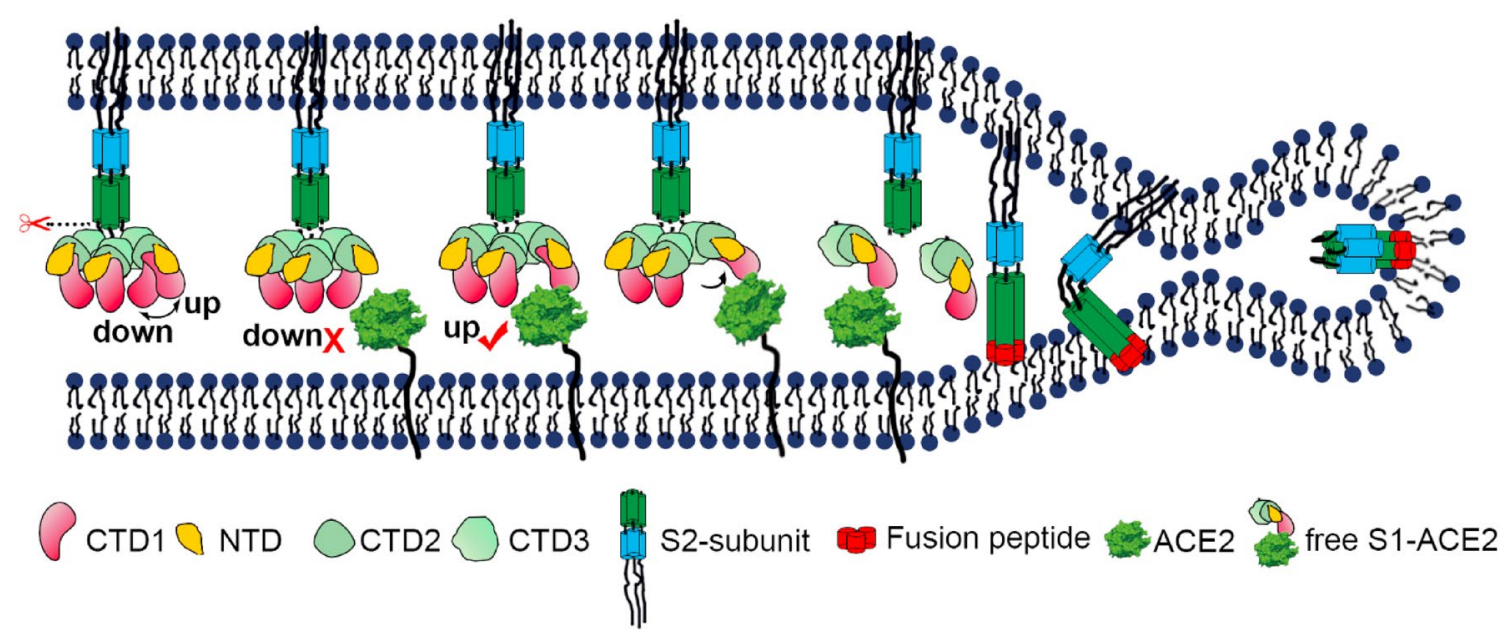

Fig. 2 Cartoon representation showing the pre- to post-fusion transition of the SARS-CoV S glycoprotein. The ${ }^{a}$ down $^{\circ}$ to ${ }^{a} \mathrm{up}^{\circ}$ transition of the receptor-binding domain (CTD1) allows receptor binding. The binding to ACE2 opens up CTD1 and CTD2, promotes the disassociation of the S1-ACE2 complex from the S1/S2 cleaved S glyco- protein, induces the pre- to post-fusion transition of the S2 subunit, and initiates the membrane fusion. Spike (S); angiotensin-converting enzyme (ACE); severe acute respiratory syndrome (SARS) From Song W. PLOS Pathogens https://doi.org/10.1371/journal.ppat.10072 36 with permission 
Fig. 3 ACE2 receptors are expressed in multiple organs, with the greatest density and potential for upregulation in the lungs, heart and blood vessels (arteries and veins; macrovessels and microvessels). There is a direct relationship between ACE2 receptor density and target organ involvement and injury among patients with COVID-19 From Zou X. Front Med https://doi.org/10.1007/ s11684-020-0754-0 with permission

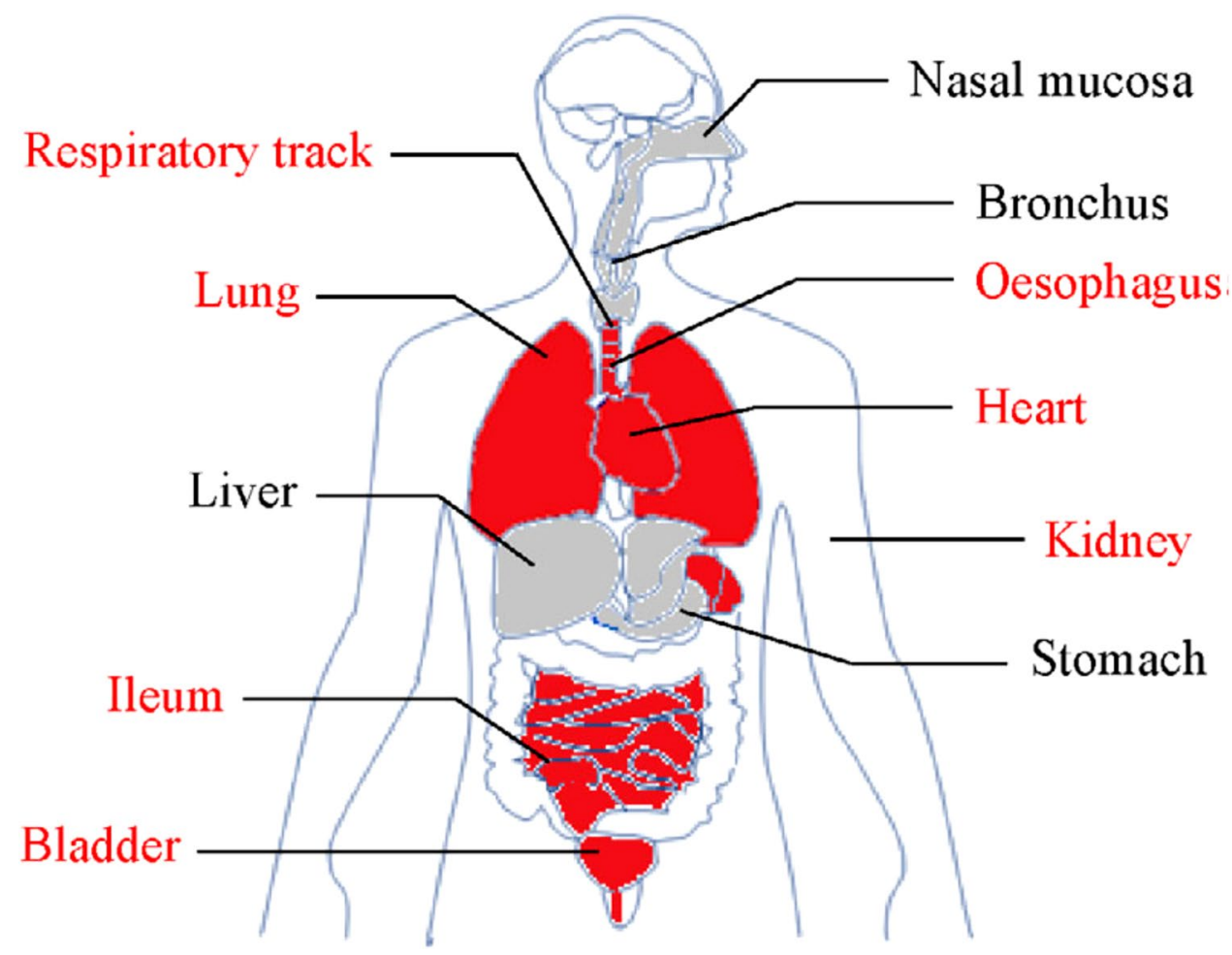

and ultimately, the phonotypic expression of disease. RNA sequencing data from human hearts show that nearly $8.0 \%$ of myocardial cells have positive ACE2 expression. This finding is of particular relevance in patients with SARS-COV-2 viremia [8] and may hold the key to a better understanding of cardiac injury, heart failure, arrhythmias and circulatory shock in COVID-19.

\section{Scope of the problem}

At the time of this writing, there were 972,203 confirmed cases of COVID-19, 50,321 deaths and 185 countries or territories with reported cases (World Health Organization situation report \# 74; April 3, 2020; www.who.int; www.cdc.gov). The overall case fatality rate of COVID19 based on published reports is $2.0-4.0 \%$; however, the statistics are changing hour-by-hour and day-by-day. What is clear and consistent is that morbidity and mortality increase significantly with age, rising to $\sim 8.0 \%$ for patients between the ages of $70-79$ and $~ 14.8 \%$ in patients greater than 80 . In addition to a recognized impairment in immune response that increases with age, comorbid illnesses, including heart, metabolic and lung disease are also more likely among older persons. Access to health care may also be impacted by age to varying degrees around the world.

\section{Predisposing factors and conditions for COVID-19}

The initial cohort of hospitalized patients with laboratory confirmed SARS-CoV-2 infections included mostly men (30 of $41 ; 73 \%$ ) and approximately one-third had underlying diseases that such as diabetes mellitus (20\%), hypertension (15\%) and cardiovascular disease (15\%). A similar profile of predisposition was reported for MERS (Middle-East Respiratory Syndrome) $[25,26]$.

$\mathrm{Li}$ et al. performed a meta-analysis of studies that summarized the prevalence of cardiovascular and metabolic disease among patients with COVID-19 [27]. A total of six studies including 1527 patients were identified. The proportion of patients with hypertension, cardiac or cerebrovascular disease and diabetes mellitus was $17.1 \%, 16.4 \%$, and $9.7 \%$, respectively. Among the most severely affected patients requiring ICU-level care, the incidence rates were two-fold, threefold and two-fold higher, respectively, when compared with patients who were able to receive treatment in a non-ICU setting. 


\section{Clinical course and cardiovascular complications of COVID-19}

All of the patients within the initial cohort of confirmed cases had pneumonia [1]. Reported complications included acute respiratory distress syndrome (ARDS) (19\%), RNAemia (15\%), and acute cardiac injury (12\%) based on a high sensitivity troponin I value above the 99th percentile of normal. Two patients were placed on veno-venous extra-corporeal membrane oxygenation (ECMO) mechanical support for refractory hypoxia. The mortality rate was $15 \%$.

There were circulating plasma factors of an inflammatory state with increased levels of interleukin (IL)- $1 \beta$, IL1RA, IL7, IL8, IL9, IL10, basic fibroblast growth factor (FGF), interferon(IFN) $)_{\mathrm{p}}$, interferon-inducible protein (IP) 10, monocyte chemoattractant protein (MCP)1, plasma membrane intrinsic protein(MIP) $1 \mathrm{~A}$, MIP1 $\beta$, plateletderived growth factor (PDGF), tumor necrosis factor (TNF)- $\alpha$ and vascular endothelial growth factor (VEGF) compared to healthy adults. The severity of COVID-19 has been linked to viral load from the upper respiratory track, acute lung injury, cardiac injury and angiotensin II plasma levels [28, 29].

In the meta-analysis performed by Li et al., $8.0 \%$ of patients with COVID -19 infection had acute cardiac injury [27]. Those who required ICU-level care had a 13-fold higher incidence of acute cardiac injury compared to those with a lower acuity but COVID-19 confirmed cohort of patients. The clinical course of COVID-19 has similarities to SARS-COV and MERS-COV that have also have been linked to fatal illness [30].

Zhou et al. [31] performed a retrospective, multi-center cohort study of 191 patients with confirmed COVID-19 from Jinyintan Hospital and Wuhan Pulmonary Hospital. A total of 137 patents were discharged and 54 patients died in hospital. A multivariable regression analysis identified an increasing likelihood of death associated with older age (OR 1.10, 95\% CI 1.03-1.17, per year increase), multi-organ system failure (OR 5.65, 95\%, CI 2.61-12.23) and a D-dimer greater than $1 \mu \mathrm{g} / \mathrm{L}$ (OR $18.42,95 \% \mathrm{CI}$ 2.64-128.55). Viral shedding was detectable in all survivors for a median of 20 days. In non-survivors, viral shedding was detectable up to the time of death.

Wang et al. [32] described the clinical characteristics of 138 patients with confirmed COVID-19 hospitalized at Zhongnoa Hospital of Wuhan University. Hospital-associated transmission was suspected for health professionals $(40[29 \%])$ and hospitalized patients $(17[12.3 \%])$. Chest CT scans revealed bilateral patchy infiltrates or ground glass opacities in all patients. Thirty-six patients $(26.1 \%)$ required ICU-level care because of ARDS (22[65.1\%]), arrhythmias (16[44.4\%]) or circulatory shock (11[30.6\%]). Four patients required veno-venous ECMO. Acute cardiac injury was present in 50 patients $(7.2 \%)$; however, 8 patients requiring ICU-level care had evidence of acute cardiac injury (22.2\%). A total of 13 patients required vasopressor or inotrope support for low blood pressure or heart failure.

The cardiovascular complications attributed to COVID19 infection were summarized by Chen et al. [8, 33]. A total of 150 consecutive patients in the Fever Clinic of Tonglin Hospital in Wuhan China served as the study population. Male sex, elevated NT (N-terminal)-pro B-type Natriuretic Peptide (BNP), elevated cTnI and history of coronary heart disease were more common in critically ill patients compared to patients with mild symptoms. In a multivariable logistic regression analysis, elevated cTnI (OR 26.9\%; 95\% CI 4.08-177.23) and a past history of coronary heart disease (OR 16.61; 95\% CI 2.28-120.58) were independently associated with a critical illness status.

Yang et al. [34] performed a retrospective, single center, study of 52 critically ill patients hospitalized in Wuhan Hin Tin-tam Hospital with COVID-19. A total of 32 (61.5\%) of patients died during a 28-day follow-up period. Non-survivors were older (64.6 years vs 51.9 years) and were more likely to develop ARDS (26[81\%] vs 9[45\%]) than survivors. A majority of infected patients who did not survive their hospitalizations had organ damage, including 35 (67\%) with ARDS, 15 (29\%) with acute kidney injury, 12 (23\%) with cardiac injury and 15 (29\%) with liver failure.

Shi et al. [35] evaluated the impact of cardiac injury on mortality in 416 hospitalized patients with COVID-19. A total of 82 patients (19.7\%) had cardiac injury. When comparing patients with to those without cardiac injury, the former were older, had a greater number of comorbid conditions, higher levels of C-reactive protein, procalcitonin and NT-pro-BNP and multilobar pneumonia. They also had a higher incidence of ARDS requiring mechanical ventilation, acute kidney injury and coagulation abnormalities. The mortality rates were $56.2 \%$ and $4.5 \%$, respectively. In a Cox regression analysis, cardiac injury was associated with a three-fourfold higher risk of death (HR 3.41; 95\% CI 1.62-7.16).

Myocarditis is known to occur in a wide range of acute viral infections, including adenovirus, human immunodeficiency virus (HIV), Epstein-Barr Virus, and influenza virus to name a few. Observational data, coupled with virologic and molecular diagnostic techniques suggest that enteroviruses, including coxsackieviruses, parvoviruses and adenoviruses are among the most common causes of myocarditis. Given the duration of viral shedding in SARS-CoV-2 infection and COVID-19, as well as the relatively high density of ACE2 receptors expressed in cardiomyocytes, one would expect to see cases of myocarditis and myopericarditis. Chen 
et al. [33] highlighted the potential for SARS-CoV-2 to be a cause of fulminant myocarditis, citing the frequency of cardiac injury and robust inflammatory response "cytokine storm" as a core pathophysiological mechanism of fulminant myocarditis. As with other viral causes of myocarditis, the presenting signs, symptoms and diagnostic features will vary from chest discomfort and shortness of breath with electrocardiographic ST-T wave abnormalities, elevated cTnI and NT-pro-BNP levels to heart failure and cardiogenic shock. An appropriate clinical index of suspicion will be required. In addition, patients with pre-existing cardiovascular disease and either ischemic or non-ischemic cardiomyopathies will be the most vulnerable to progressive or precipitous change in ventricular performance and clinical decompensation.

The pivotal questions that the medical and scientific communities must answer are, "why do elevated cardiac biomarkers portend a worse prognosis among patients with COVID-19"? Are they an epiphenomenon of infection severity? Do they reflect vital organ viral load, viremia and/or direct myocardial or microvessel invasion of SARS-CoV-2? Might they be a marker of a systemic inflammatory response and a "red flag" for impending "cytokine storm"?

\section{Pediatric populations and COVID-19}

While adults have been the most severely affected by COVID-19, emerging data show that infants, children and adolescents have contracted SARS-CoV-2 as well [36]. In a nation-wide case series of 2143 pediatric patients reported to the Chinese Center for Disease Control and Prevention, there were 731 laboratory-confirmed and 1412 suspected cases. The median age was 7 years (interquartile range $2-13)$. While $90 \%$ of cases were considered mild in severity, there were severe and critically ill patients as well. The proportion of severe and critical cases was greatest for the age group $<1$ year $(10.6 \%)$ and $1-5$ years of age $(7.3 \%)$ with critical illness features, including ARDS, encephalopathy, myocardial injury, heart failure and circulatory shock. Case series from other centers and from other countries have underscored the potential impact of COVID-19 on neonates, infants, children and adolescents [37-40]. There is also an impact on neonates born to mothers who are infected at the time of delivery [41].

\section{Management of COVID-19}

In addition to early diagnosis and supportive care, the American College of Cardiology has emphasized the importance of cardiac complications in patients with COVID-19 and their optimal management to include assisting other clinical specialties, being prepared to treat critically ill patients with advanced medical and mechanical therapies such as ECMO (veno-venous and veno-arterial) and recommending diagnostic testing such as echocardiography in patients with heart failure, arrhythmias, electrocardiographic (ECG) abnormalities or cardiomegaly on chest X-ray. (ACC Clinical Bulletin-COVID-19 Clinical Guidance for the CV Care Team; March 2020) (Table 1).

\section{Impact of medications on susceptibility or severity of COVID-19}

The expression of ACE2 is increased among patients with diabetes mellitus and in patients treated with either ACE inhibitors or angiotensin receptor blockers [42]. While one could postulate that treatment with either an ACE-I or ARB predisposes patients to SARS-CoV-2 infection, there are insufficient data to make a recommendation to clinicians or patients to either avoid or transition to alternative treatments. This position was emphasized recently in a joint statement from the American Heart Association, American College of Cardiology and the Heart Failure Society of America (websites accessed March 17, 2020, www.heart.org). The potential of statins, through their ability to reduce inflammation, to impact the severity of COVID-19 is untested.

Table 1 COVID-19 Clinical guidance for clinicians involved with the care of patients with suspected or laboratory-confirmed COVID-19 infection From: ACC Clinical Bulletin-COVID-19 Clinical Guidance for the CV Care Team; March 2020

Devise clear plans to quickly identify and isolate patients with CVD and COVID-19 symptoms

Advise all patients with CVD of the heightened risk for contracting COVID-19 and provide instruction for precaution

In geographies with active COVID-19 outbreaks, telephonic or telehealth options should be considered in place for n-patient visits for patients with stable CVD

Be aware that classic signs and symptoms of acute myocardial infarction may be overshadowed in the setting of COVID-19 infection

Devise specific protocols for the management of acute myocardial infarction in the context of COVID-19 infection

Place particular emphasis on acute PCI and CABG

Craft protocols to limit catheterization and operating room time for staff, provide personnel protection and assess post-procedural sterilization

Carefully assess the risk-benefit of less urgent PCI or CABG

Providers should be mindful of their own health that requires adequate sleep and good eating habits. 


\section{Treatment of COVID-19}

There is not an FDA-approved treatment for COVID-19 at this time; however, substantial effort is being undertaken by the National Institutes of Health, World Health Organization, private foundations and the pharmaceutical industry. On March 28, 2020 the FDA issued an emergency use authorization (EUA) permitting chloroquine phosphate (medical grade) and hydroxychloroquine sulfate to be added to the strategic national stockpile (SNS). The SNS exists under the authority of the US Department of Health and Human Services (HHS) and accepted 30 million doses of hydroxychloroquine sulfate donated by Sandoz, the Novartis generics and biosimilars division, and one million doses of chloroquine phosphate donated by Bayer Pharmaceuticals for potential use in treating patients who are hospitalized with COVID-19 or for use in clinical trials. In addition, the SNS donations, these companies and potentially others can offer additional doses and will likely accelerate production for commercial markets (www.fda. gov).

An open-label trial of 199 patients with laboratory confirmed SARS-CoV-2 and severe COVID-19 compared Lopinavir-Rhonavir versus standard care. There were no differences in the time to clinical improvement, detectable viral RNA at various time points or 28 days mortality [43].

The WHO has embarked on a mega-trial known as SOLIDARITY that will test 4 drugs:remdesivir; the malaria medications chloroquine and hydroxychloroquine; a combination of two HIV drugs, Lopinavir and Ritonavir; and that same combination plus interferon-beta, an immune system modulatory. A pragmatic trial design will be employed. When a person with a confirmed case of COVID-19 is deemed eligible, the physician can enter the patient's data into a WHO website, including co-morbid conditions, such as diabetes, cardiovascular disease or HIV infection. The participant has to sign an informed consent form that is scanned and sent to WHO electronically. After the physician states which drugs are available at his or her hospital, the website will randomize the patient to one of the drugs available or to the local standard care for COVID-19. A global data safety monitoring board will perform an interim analyses at regular intervals and determine whether any of the drugs has a clear beneficial effect, or whether one or more drugs can be dropped because they do not offer benefit. The first patients have recently been enrolled. Other drugs could be tested employing the SOLIDARITY trial network (www.who.int).

Inserm, founded in 1964, is a public scientific and technological institute which operates under the joint authority of the French Ministries of Health and Research. It announced recently that it will coordinate an add-on trial in Europe, Discovery, that will follow the WHO's methods and include 3200 patients from at least seven countries, including 800 from France. That trial will test the same drugs, with the exception of chloroquine (www.inser m.com).

Remdesivir is a nucleotide analog prodrug that incorporates into nascent viral RNA chains and results in premature termination. The effects occur post-viral entry [44]. Chloroquine is known to inhibit virus infection by increasing endosomal $\mathrm{pH}$ required for virus-cell fusion, and interferes with glycosylation of cellular receptors of SARS-CoV-2. It functions at both entry and post-entry stages of virus infection.

Gilead Sciences, Foster City, CA (www.gilead.com) has embarked upon two phase III clinical trials testing its antiviral drug, remdesivir, for the treatment of COVID-19 in adults. The randomised, open-label, multi-center studies will assess the safety and efficacy of the drug in nearly 1000 patients. A five-day and ten-day dosing regimen of an intravenous formulation of remdesivir will be tested. The trials will mainly be conducted at sites in Asian countries, however, sites from other countries will likely be added. One of the trials will enroll approximately 400 patients with severe COVID-19, while the second trial will include approximately 600 patients with moderate severity COVID19. Clinical improvement will be the primary outcome measure. In the first trial, normalization of temperature and oxygen saturation will be the focus. The second trial will record these measures based on the proportion of patients discharged by day 14 . With the addition of the two phase III clinical trials, there are currently five trials of remdesivir in the treatment of COVID-19. Results from at least one of the trials initiated in China is expected in the coming weeks.

The National Institute of Allergy and Infectious Diseases (www.nih.gov) is conducting a randomized, controlled trial to evaluate the safety and efficacy of remdesivir in adults hospitalized with COVID-19. The trial is being conducted at The University of Nebraska Medical Center. All potential subjects undergo a baseline physical examination before receiving treatment with either the investigational treatment or placebo in addition to standards of care. Participants in the investigational treatment group will receive $200 \mathrm{mg}$ of remdesivir intravenously on the first day of enrollment to the study. They will receive another $100 \mathrm{mg}$ each day for the duration of hospitalization, for up to 10 days. Clinicians will regularly monitor participants and will assign them daily scores based on a predefined scale of clinical outcomes that consider factors, including body temperature, blood pressure and use of supplemental oxygen. Participants also will be asked to provide blood samples and nose and throat swabs approximately every two days that will be analyzed for SARS-CoV-2. The NIAID will expand the Adaptive COVID-19 Treatment Trial (ACTT) to as many as 75 sites globally and include 440 subjects. 
Convalescent plasma derived from patients with laboratory confirmed SARS-CoV-2 infection and absent viral shedding could be considered for passive immune therapy [45].Given the public health emergency that the expanding COVID-19 outbreak presents, and while clinical trials are being conducted, the FDA is facilitating access to COVID19 convalescent plasma for use in patients with serious or immediately life-threatening COVID-19 infections through a single patient emergency Investigational New Drug Applications (eINDs) for Individual patients under 21 code of federal regulations (CFR) 312.310. This process allows the use of an investigational drug for the treatment of an individual patient by a licensed physician upon FDA authorization. This does not include the use of COVID-19 convalescent plasma for the prevention of infection. Monoclonal antibody administration has also been suggested [46]. In addition, SARS-CoV RBD-specific antibodies could cross-react with SARS-CoV-2 receptor-binding domain (RBD) protein, and SARS-CoV RBD-induced antisera could cross-neutralize SARS-CoV-2 [47]. Rigorous clinical trials will be required to determine the safety and efficacy of monoclonal antibody administration.

At the time of this writing there were 287 clinical trials to study COVID-19 registered in the Clinical Trials.Gov (www.clinicaltrials.gov).

\section{SARS-CoV-2 vaccine development}

Identifying potential targets for a SARS-CoV-2 vaccine must take full advantage of the high genetic similarity with SARS-CoV [48] and be ever mindful of safety considerations. Prior investigations by Ahmed et al. identified B cell and $\mathrm{T}$ cell epitopes derived from $\mathrm{S}$-proteins and $\mathrm{N}$-proteins that mapped identically to corresponding SARS-CoV-2 proteins [49]. Immune targeting of these epitopes could be the basis for vaccine development, potentially on a global scale if mutations in the epitope sequences are not identified from different parts of the world [50].

In the United States, the first participant has been dosed in the Phase I study of Moderna's ${ }^{\mathrm{TM}}$ mRNA vaccine (mRNA1273) against the novel Coronavirus (SARS-CoV-2).The National Institutes of Health (NIH) is conducting the trial under its own investigational new drug (IND) application. The Phase I study will enroll 45 healthy adults to evaluate the safety and immunogenicity of $25 \mu \mathrm{g}, 100 \mu \mathrm{g}, 250 \mu \mathrm{g}$ dose levels of mRNA-1273 administered on a two-dose vaccination schedule (www.fda.gov).

Researchers at China's Academy of Military Medical Sciences have reportedly received approval to launch earlystage clinical trials of a potential Coronavirus (COVID-19) vaccine starting this week (English.nmpa.gov.cn).According to the Chinese clinical trial registration database (NMPA), a Phase I test evaluating the safety of the experimental shot in humans intends to recruit 108 healthy people between 16 March and 31 December. China's Academy of Military Medical Sciences and the Hong Kong-listed biotech company CanSino Biologics ${ }^{\mathrm{TM}}$ will conduct the clinical trial.

Pfizer $^{\mathrm{TM}}$ recently announced that it has joined forces with German biotech company BioNTech ${ }^{\mathrm{TM}}$ to develop a potential RNA vaccine to prevent the spread of COVID-19. The collaboration will focus on the potential speed that RNA vaccines can be constructed and unique mechanism(s) of effect.RNA vaccines work by introducing a type of RNA (containing the genetic sequence), which is produced without growing the virus, into the body. The cells then use this information to build an antigen, which is specific to the virus. The immune system then recognizes the antigen and builds up immunity against it (www.pfizer.com; www.break throughs.com).

At the time of this writing, there were five COVID-19 vaccine clinical trials registered at clinical trials.gov (www. clinicaltrials.gov). According to the WHO website, there are 48 vaccines in preclinical development (www.who.int). Clinical trials of Bacillus-Calmette-Guerin (BCG) vaccine have recently been initiated around the world. The scientific premise for study is based on prior observations that vaccinated individuals are not only protected from tuberculosis, but viral and parasitic infections as well.

\section{Concluding thoughts and future directions}

The emergence of a new strain of Coronavirus, SARS$\mathrm{CoV}-2$, as a cause of COVID-19 represents an unprecedented period in history for the lay, medical and scientific communities. While each is working closely together and learning from one-another, additional efforts are needed. The available information derived from case studies show that COVID-19 has both direct and indirect cardiovascular effects, ranging from cardiac injury to myocarditis, arrhythmias, respiratory failure requiring mechanical ventilation and veno-venous ECMO and circulatory failure requiring inotropes, vasopressors and veno-arterial ECMO. Clinicians must also be aware that COVID-19 can over-shadow acute cardiac events, including ST segment elevation myocardial infarction [51] or delay treatment given current strains on emergency rooms and emergency medical services. They must maintain an appropriate level of balanced, full-field vision in the midst of a global event with a dominating presence in everyone's mind. Last, at the time of this writing there were 1528 references on the topic of SARS-CoV-2 and COVID-19 cited in PubMed. This represents a $1000+$ publication increase in the past 5 days. While the wealth of information no doubt reflects an extraordinary level of interest and 
commitment to a world-wide health threat; we must all be vigilant in our interpretation of the published literature, its source, level of scientific rigor and potential translation to scientific and clinical advances.

\section{References}

1. Huang C, Wang Y, Li X, Ren L, Zhao J, Hu Y, Zhang L, Fan G, Xu J, Gu X, Cheng Z, Yu T, Xia J, Wei Y, Wu W, Xie X, Yin W, Li H, Liu M, Xiao Y, Gao H, Guo L, Xie J, Wang G, Jiang R, Gao Z, Jin Q, Wang J, Cao B (2020) Clinical features of patients infected with 2019 novel Coronavirus in Wuhan, China. Lancet 395:497-506

2. Zhu N, Zhang D, Wang W, Li X, Yang B, Song J, Zhao X, Huang B, Shi W, Lu R, Niu P, Zhan F, Ma X, Wang D, Xu W, Wu G, Gao GF, Tan W (2020) A novel Coronavirus from patients with pneumonia in China, 2019. N Engl J Med 382:727-733

3. Holshue ML, DeBolt C, Lindquist S, Lofy KH, Wiesman J, Bruce H, Spitters C, Ericson K, Wilkerson S, Tural A, Diaz G, Cohn A, Fox L, Patel A, Gerber SI, Kim L, Tong S, Lu X, Lindstrom S, Pallansch MA, Weldon WC, Biggs HM, Uyeki TM, Pillai SK (2020) First case of 2019 novel Coronavirus in the United States. N Engl J Med 382:929-936

4. Ceraolo C, Giorgi FM (2020) Genomic variance of the 2019nCoV Coronavirus. J Med Virol 92:522-528

5. Sah R, Rodriguez-Morales AJ, Jha R, Chu DKW, Gu H, Peiris M, Bastola A, Lal BK, Ojha HC, Rabaan AA, Zambrano LI, Costello A, Morita K, Pandey BD, Poon LLM (2020) Complete genome sequence of a 2019 novel Coronavirus (SARS-CoV-2) strain isolated in Nepal. Microbiol Resour Announc. https://doi. org/10.1128/MRA.00169-20

6. Wu F, Zhao S, Yu B, Chen YM, Wang W, Song ZG, Hu Y, Tao ZW, Tian JH, Pei YY, Yuan ML, Zhang YL, Dai FH, Liu Y, Wang QM, Zheng JJ, Xu L, Holmes EC, Zhang YZ (2020) A new Coronavirus associated with human respiratory disease in China. Nature 579:265-269

7. Harcourt J, Tamin A, Lu X, Kamili S, Sakthivel SK, Murray J, Queen K, Tao Y, Paden CR, Zhang J, Li Y, Uehara A, Wang H, Goldsmith C, Bullock HA, Wang L, Whitaker B, Lynch B, Gautam R, Schindewolf C, Lokugamage KG, Scharton D, Plante JA, Mirchandani D, Widen SG, Narayanan K, Makino S, Ksiazek TG, Plante KS, Weaver SC, Lindstrom S, Tong S, Menachery VD, Thornburg NJ (2020) Severe acute respiratory syndrome Coronavirus 2 from patient with 2019 novel Coronavirus disease, United States. Emerg Infect Dis. https://doi.org/10.3201/eid2606.200516

8. Chen W, Lan Y, Yuan X, Deng X, Li Y, Cai X, Li L, He R, Tan Y, Deng X, Gao M, Tang G, Zhao L, Wang J, Fan Q, Wen C, Tong Y, Tang Y, Hu F, Li F, Tang X (2020) Detectable 2019-nCoV viral RNA in blood is a strong indicator for the further clinical severity. Emerg Microb Infect 9:469-473

9. Walls AC, Park YJ, Tortorici MA, Wall A, McGuire AT, Veesler D (2020) Structure, function, and antigenicity of the SARSCoV-2 spike glycoprotein. Cell. https://doi.org/10.1016/j. cell.2020.02.058

10. Wrapp D, Wang N, Corbett KS, Goldsmith JA, Hsieh CL, Abiona O, Graham BS, McLellan JS (2020) Cryo-EM structure of the 2019-nCoV spike in the prefusion conformation. Science 367:1260-1263

11. Chen Y, Liu Q, Guo D (2020) Emerging Coronaviruses: genome structure, replication, and pathogenesis. J Med Virol 92:418-423

12. Fung TS, Liu DX (2019) Human Coronavirus: host-pathogen interaction. Annu Rev Microbiol 73:529-557
13. Song W, Gui M, Wang X, Xiang Y (2018) Cryo-EM structure of the SARS Coronavirus spike glycoprotein in complex with its host cell receptor ACE2. PLoS Pathog 14:e1007236

14. Li C, Yang Y, Ren L (2020) Genetic evolution analysis of 2019 novel Coronavirus and Coronavirus from other species. Infect Genet Evol: J Mol Epidemiol Evol Genet Infect Dis 82:104285

15. Shen Z, Xiao Y, Kang L, Ma W, Shi L, Zhang L, Zhou Z, Yang J, Zhong J, Yang D, Guo L, Zhang G, Li H, Xu Y, Chen M, Gao Z, Wang J, Ren L, Li M (2020) Genomic diversity of SARSCoV-2 in Coronavirus disease 2019 patients. Clin Infect Dis. https://doi.org/10.1093/cid/ciaa203/5780800

16. Tang JW, Tambyah PA, Hui DSC (2020) Emergence of a novel Coronavirus causing respiratory illness from Wuhan, China. J Infect 80:350-371

17. Wan Y, Shang J, Graham R, Baric RS, Li F (2020) Receptor recognition by the novel Coronavirus from Wuhan: an analysis based on decade-long structural studies of SARS Coronavirus. J Virol. https://doi.org/10.1128/JVI.00127-20

18. Tang X, Wu C, Li X, Song Y, Yao X, Wu X, Duan Y, Zhang H, Wang Y, Qian Z, Cui J, Lu J (2020) On the origin and continuing evolution of SARS-CoV-2. Natl Sci Rev. https://doi. org/10.1093/nsr/nwaa036/5775463

19. Liu Q, Zhou YH, Yang ZQ (2016) The cytokine storm of severe influenza and development of immunomodulatory therapy. Cell Mol Immunol 13:3-10

20. Zou L, Ruan F, Huang M, Liang L, Huang H, Hong Z, Yu J, Kang M, Song Y, Xia J, Guo Q, Song T, He J, Yen HL, Peiris M, Wu J (2020) SARS-CoV-2 viral load in upper respiratory specimens of infected patients. N Engl J Med 382:1177-1179

21. Zou X, Chen K, Zou J, Han P, Hao J, Han Z (2020) Singlecell RNA-seq data analysis on the receptor ACE2 expression reveals the potential risk of different human organs vulnerable to 2019-nCoV infection. Front Med. https://doi.org/10.1007/ s11684-020-0754-0

22. Hamming I, Timens W, Bulthuis M, Lely A, Navis G, van Goor $\mathrm{H}$ (2004) Tissue distribution of ACE2 protein, the functional receptor for SARS Coronavirus A first step in understanding SARS pathogenesis. J Pathol 203:631-637

23. Qi F, Qian S, Zhang S, Zhang Z (2020) Single cell RNA sequencing of 13 human tissues identify cell types and receptors of human Coronaviruses. Biochem Biophys Res Commun. https://doi.org/10.1016/j.bbrc.2020.03.044

24. Pasanen L, Launonen H, Siltari A, Korpela R, Vapaatalo H, Salmenkari H, Forsgard RA (2019) Age-related changes in the local intestinal renin-angiotensin system in normotensive and spontaneously hypertensive rats. J Physiol Pharmacol. https:// doi.org/10.26402/jpp.2019.2.03.pdf

25. Zaki AM, van Boheemen S, Bestebroer TM, Osterhaus AD, Fouchier RA (2012) Isolation of a novel Coronavirus from a man with pneumonia in Saudi Arabia. N Engl J Med $367: 1814-1820$

26. Assiri A, Al-Tawfiq JA, Al-Rabeeah AA, Al-Rabiah FA, AlHajjar S, Al-Barrak A, Flemban H, Al-Nassir WN, Balkhy HH, Al-Hakeem RF, Makhdoom HQ, Zumla AI, Memish ZA (2013) Epidemiological, demographic, and clinical characteristics of 47 cases of Middle East respiratory syndrome Coronavirus disease from Saudi Arabia: a descriptive study. Lancet Infect Dis 13:752-761

27. Li B, Yang J, Zhao F, Zhi L, Wang X, Liu L, Bi Z, Zhao Y (2020) Prevalence and impact of cardiovascular metabolic diseases on COVID-19 in China. Clin Res Cardiol. https://doi.org/10.1007/ s00392-020-01626-9

28. Fu Y, Cheng Y, Wu Y (2020) Understanding SARS-CoV-2-mediated inflammatory responses: from mechanisms to potential therapeutic tools. Virol Sin. https://doi.org/10.1007/s12250-020-00207 $-4$ 
29. Liu Y, Yang Y, Zhang C, Huang F, Wang F, Yuan J, Wang Z, Li J, Li J, Feng C, Zhang Z, Wang L, Peng L, Chen L, Qin Y, Zhao D, Tan S, Yin L, Xu J, Zhou C, Jiang C, Liu L (2020) Clinical and biochemical indexes from 2019-nCoV infected patients linked to viral loads and lung injury. Sci China Life Sci 63:364-374

30. Leung C (2020) Clinical features of deaths in the novel Coronavirus epidemic in China. Rev Med Virol. https://doi.org/10.1002/ rmv. 2103

31. Zhou P, Yang XL, Wang XG, Hu B, Zhang L, Zhang W, Si HR, Zhu Y, Li B, Huang CL, Chen HD, Chen J, Luo Y, Guo H, Jiang RD, Liu MQ, Chen Y, Shen XR, Wang X, Zheng XS, Zhao K, Chen QJ, Deng F, Liu LL, Yan B, Zhan FX, Wang YY, Xiao GF, Shi ZL (2020) A pneumonia outbreak associated with a new Coronavirus of probable bat origin. Nature 579:270-273

32. Wang D, Hu B, Hu C, Zhu F, Liu X, Zhang J, Wang B, Xiang H, Cheng Z, Xiong Y, Zhao Y, Li Y, Wang X, Peng Z (2020) Clinical characteristics of 138 hospitalized patients with 2019 novel Coronavirus-infected pneumonia in Wuhan, China. JAMA. https ://doi.org/10.1001/jama.2020.1585

33. Chen C, Zhou Y, Wang DW (2020) SARS-CoV-2: a potential novel etiology of fulminant myocarditis. Herz. https://doi. org/10.1007/s00059-020-04909-Z

34. Yang X, Yu Y, Xu J, Shu H, Xia J, Liu H, Wu Y, Zhang L, Yu Z, Fang M, Yu T, Wang Y, Pan S, Zou X, Yuan S, Shang Y (2020) Clinical course and outcomes of critically ill patients with SARS-CoV-2 pneumonia in Wuhan, China: a single-centered, retrospective, observational study. Lancet Respir Med. https://doi. org/10.1016/S2213-2600(20)30079-5

35. Shi S, Qin M, Shen B, Cai Y, Liu T, Yang F, Gong W, Liu X, Liang J, Zhao Q, Huang H, Yang B, Huang C (2020) Association of cardiac injury with mortality in hospitalized patients with COVID-19 in Wuhan, China. JAMA Cardiol. https://doi. org/10.1001/jamacardio.2020.0950

36. Dong Y, Mo X, Hu Y, Qi X, Jiang F, Jiang Z, Tong S (2020) Epidemiological characteristics of 2143 pediatric patients with 2019 Coronavirus disease in China. Pediatrics. https://doi.org/10.1542/ peds.2020-0702

37. Zheng F, Liao C, Fan QH, Chen HB, Zhao XG, Xie ZG, Li XL, Chen CX, Lu XX, Liu ZS, Lu W, Chen CB, Jiao R, Zhang AM, Wang JT, Ding XW, Zeng YG, Cheng LP, Huang QF, Wu J, Luo XC, Wang ZJ, Zhong YY, Bai Y, Wu XY, Jin RM (2020) Clinical characteristics of children with Coronavirus disease 2019 in Hubei, China. Curr Med Sci. https://doi.org/10.1007/s1159 6-020-2172-6

38. Li Y, Guo F, Cao Y, Li L, Guo Y (2020) Insight into COVID2019 for pediatricians. Pediatr Pulmonol. https://doi.org/10.1002/ ppul.24734

39. Xia W, Shao J, Guo Y, Peng X, Li Z, Hu D (2020) Clinical and CT features in pediatric patients with COVID-19 infection: different points from adults. Pediatr Pulmonol. https://doi.org/10.1002/ ppul.24718

40. Shen K, Yang Y, Wang T, Zhao D, Jiang Y, Jin R, Zheng Y, Xu B, Xie Z, Lin L, Shang Y, Lu X, Shu S, Bai Y, Deng J, Lu M, Ye L, Wang X, Wang Y, Gao L (2020) Diagnosis, treatment, and prevention of 2019 novel Coronavirus infection in children: experts' consensus statement. WJP. https://doi.org/10.1007/s12519-02000343-7

41. Zhu H, Wang L, Fang C, Peng S, Zhang L, Chang G, Xia S, Zhou W (2020) Clinical analysis of 10 neonates born to mothers with 2019-nCoV pneumonia. Transl Pediatr 9:51-60
42. Patel AB, Verma A (2020) COVID-19 and angiotensin-converting enzyme inhibitors and angiotensin receptor blockers: what is the evidence? JAMA. https://doi.org/10.1001/jama.2020.4812

43. Cao B, Wang Y, Wen D, Liu W, Wang J, Fan G, Ruan L, Song B, Cai Y, Wei M, Li X, Xia J, Chen N, Xiang J, Yu T, Bai T, Xie X, Zhang L, Li C, Yuan Y, Chen H, Li H, Huang H, Tu S, Gong F, Liu Y, Wei Y, Dong C, Zhou F, Gu X, Xu J, Liu Z, Zhang Y, Li H, Shang L, Wang K, Li K, Zhou X, Dong X, Qu Z, Lu S, Hu X, Ruan S, Luo S, Wu J, Peng L, Cheng F, Pan L, Zou J, Jia C, Wang J, Liu X, Wang S, Wu X, Ge Q, He J, Zhan H, Qiu F, Guo L, Huang C, Jaki T, Hayden FG, Horby PW, Zhang D, Wang C (2020) A Trial of Lopinavir-Ritonavir in adults hospitalized with severe Covid-19. N Engl J Med. https://doi.org/10.1056/NEJMo a2001282

44. Wang M, Cao R, Zhang L, Yang X, Liu J, Xu M, Shi Z, Hu Z, Zhong W, Xiao G (2020) Remdesivir and chloroquine effectively inhibit the recently emerged novel Coronavirus (2019-nCoV) in vitro. Cell Res 30:269-271

45. Zhang L, Liu Y (2020) Potential interventions for novel Coronavirus in China: a systematic review. J Med Virol 92:479-490

46. Shanmugaraj B, Siriwattananon K, Wangkanont K, Phoolcharoen W (2020) Perspectives on monoclonal antibody therapy as potential therapeutic intervention for Coronavirus disease-19 (COVID19). Asian Pac J Allergy Immunol 38:10-18

47. Yuan Y, Cao D, Zhang Y, Ma J, Qi J, Wang Q, Lu G, Wu Y, Yan J, Shi Y, Zhang X, Gao GF (2017) Cryo-EM structures of MERS$\mathrm{CoV}$ and SARS-CoV spike glycoproteins reveal the dynamic receptor binding domains. Nat Commun 8:15092

48. Ahmed SF, Quadeer AA, McKay MR (2020) Preliminary identification of potential vaccine targets for the COVID-19 Coronavirus (SARS-CoV-2) based on SARS-CoV immunological studies. Viruses 12:254

49. Chen WH, Chag SM, Poongavanam MV, Biter AB, Ewere EA, Rezende W, Seid CA, Hudspeth EM, Pollet J, McAtee CP, Strych U, Bottazzi ME, Hotez PJ (2017) Optimization of the production process and characterization of the yeast-expressed SARS-CoV recombinant receptor-binding domain (RBD219-N1), a SARS vaccine candidate. J Pharm Sci 106:1961-1970

50. Jiang S, Bottazzi ME, Du L, Lustigman S, Tseng CT, Curti E, Jones K, Zhan B, Hotez PJ (2012) Roadmap to developing a recombinant Coronavirus $S$ protein receptor-binding domain vaccine for severe acute respiratory syndrome. Expert Rev Vaccines 11:1405-1413

51. Tam CF, Cheung KS, Lam S, Wong A, Yung A, Sze M, Lam YM, Chan C, Tsang TC, Tsui M, Tse HF, Siu CW (2020) Impact of Coronavirus disease 2019 (COVID-19) outbreak on ST-segment-elevation myocardial infarction care in Hong Kong, China. Circ Cardiovasc Qual Outcomes. https://doi.org/10.1161/CIRCO UTCOMES.120.006631

Publisher's Note Springer Nature remains neutral with regard to jurisdictional claims in published maps and institutional affiliations. 